\title{
Aprendizagem móvel: uma proposta de letramento literário com auxílio de recursos digitais
}

\author{
Nataniel Mendes da Silva - IFMA/UMinho - nataniel@ifma.edu.br \\ Maria Altina Silva Ramos - UMinho - altina@ie.uminho.pt \\ Márcia Manir Miguel Feitosa - UFMA - marciamanir@hotmail.com
}

\begin{abstract}
RESUMO - O presente trabalho é resultado de uma das etapas de uma pesquisa de doutoramento sobre a integração de metodologias ativas e TIC para a promoção de experiências de aprendizagem na disciplina de literatura no Ensino Médio. Adotamos aqui, a partir de uma pesquisa bibliográfica, o paradigma do letramento literário para o ensino e aprendizagem de literatura. Em seguida, por meio de uma pesquisa exploratória e descritiva, buscamos, na literatura e na Web, aplicações para dispositivos móveis que possam enriquecer a aprendizagem de literatura. Como resultado, apresentamos uma proposta de ensino e aprendizagem do conto "Um rastro do teu sangue na neve", de Gabriel García Márquez, que integra uma metodologia para o ensino, tecnologias móveis e estímulo a uma aprendizagem ativa. O texto selecionado faz parte do livro Doze contos peregrinos, publicado em 1992.
\end{abstract}

Palavras-chave: ensino; aprendizagem; tecnologias móveis; letramento literário.

\section{Mobile learning: a literary literacy proposal with the aid of digital resources}

\begin{abstract}
This work is the result of one of the stages of a $\mathrm{PhD}$ research on the integration of active methodologies and ICT in order to promote learning experiences in the subject of literature in High School. We have here adopted, as from a bibliographic research, the paradigm of literary literacy for the teaching and learning of literature. Forthwith, through an exploratory and descriptive research, we seek, in literature and on the Web, applications for mobile devices that could enrich the learning of literature. As a result, we present a teaching and learning proposal for the tale "The Trail Of Your Blood In The Snow" by Gabriel García Márquez, which integrates a methodology for teaching, mobile technologies and encouragement to an active learning. The chosen text is integrated in the book "Strange Pilgrims", published in 1992.
\end{abstract}

Keywords: teaching; learning; mobile technologies; literary literacy.

\section{Introdução}

A onipresença de dispositivos móveis com acesso à Internet nas escolas, sobretudo em contextos urbanos, tem fomentado inúmeras discussões e pesquisas acadêmicas, no sentido de incorporá-los às práticas pedagógicas. Temas como aprendizagem móvel, aprendizagem ubíqua, educação não-formal, educação informal caminham paralelamente às, não tão novas, possibilidades de acesso à informação que tablets e smartphones oferecem. A efervescência das reflexões advém da natureza dinâmica da sociedade que engendra transformações necessárias na escola, sob pena de tornar-se obsoleta, anacrônica ou, mesmo, em um cenário para os mais pessimistas, prescindível.

Claro que essa visão pessimista não se coaduna com aquilo que deve ser o ofício de um professor-pesquisador: a busca por metodologias/estratégias e recursos que fomentem as práticas de ensino e aprendizagem, tão caras ao processo pedagógico.

Nessa busca, escola, enquanto instituição, e professores, enquanto profissionais da educação, precisam estar em sintonia com as demandas do século XXI, especialmente no que tange ao desenvolvimento de competências digitais para uma participação responsável e, sobretudo, cidadã neste tempo marcado pela fluidez com que as informações percorrem as redes. Lucas, M., e Moreira, A. (2017) apontam a literacia de V. $18 \mathrm{~N}^{\mathrm{o}} 1$, julho, 2020 RENOTE DOI: 
informação e de dados, comunicação e colaboração, criação de conteúdo digital, segurança e resolução de problemas como competências digitais importantes para o desenvolvimento pessoal e inclusão social. Essa busca deve considerar, ainda, que os smartphones são uma realidade e que os jovens, de modo geral, fazem uso diário desses dispositivos. A escola, portanto, precisa fazer dessa prática uma grande aliada na construção do saber.

Em se tratando de ensino e aprendizagem de Literatura no Ensino Médio, interessa-nos saber: como incorporar métodos assentes na relação entre leitura literária, Tecnologias da Informação e Comunicação (TIC) e estímulo a uma atitude ativa dos alunos? Para tanto, consideramos o letramento literário proposto por Cosson (2019) e buscamos na Web, e na literatura especializada, aplicativos que pudessem ser utilizados para $o$ desenvolvimento de uma sequência básica de letramento literário. A título de exemplificação, selecionamos o conto "Um rastro do teu sangue na neve", do livro Doze contos peregrinos, publicado em 1992, do escritor colombiano Gabriel García Márquez. $\mathrm{O}$ resultado é fruto de uma das etapas de uma pesquisa de doutoramento sobre a integração de metodologias ativas e TIC para a promoção das experiências de aprendizagem de literatura, desenvolvida na Universidade do Minho e que tem o apoio da Fundação de Amparo à Pesquisa e ao Desenvolvimento Científico e Tecnológico do Maranhão, FAPEMA.

\section{Literatura: ensinar e aprender}

Uma expressão artística, como é o caso da literatura, quando ganha status de disciplina escolar, não passa incólume aos problemas que naturalmente surgem nesse processo. Com frequência, alunos questionam sua necessidade e os critérios de seleção desta ou daquela obra; professores-pesquisadores discutem como ensiná-la e avaliá-la, discutem ainda se é possível ensiná-la ou somente estimular os alunos para que tenham uma experiência literária absolutamente livre e descomprometida.

Longe de elucidar todas essas querelas, que são muito pertinentes, o intento aqui é tão somente apresentar o referencial teórico, que orienta o desenvolvimento desta pesquisa sobre literatura em contexto escolar e sua aproximação com as TIC.

Os benefícios da leitura e a necessidade de formação de leitores são incontestáveis. A discussão fica em torno do papel da escola diante dessa necessidade e das estratégias que podem ser utilizadas pelos professores nas aulas e, porque não dizer em tempos de cibercultura, fora delas.

Primeiramente precisamos reconhecer os problemas para superá-los. Na disciplina de Literatura, a leitura do texto literário, e não o estudo dos meios para seu acesso, deve ser a finalidade, conforme nos alerta Todorov (2014). Estudar uma historiografia da literatura, com demarcação de datas, livros, características de escolas literárias ou dedicar-se por horas ao conhecimento da biografia dos autores não podem ser o foco da disciplina, em detrimento dos textos e das experiências que eles podem suscitar. Chiappini (2002) destaca que tradicionalmente nas aulas de literatura os alunos são estimulados a memorizar datas e tendências literárias. Cereja $(2004$, p.8) afirma que, "nas aulas de literatura, o texto literário tem tido uma importância pequena. Em vez de ele ser o centro das interações em sala de aula, na verdade cumpre esse papel um discurso didático sobre a historiografia literária”. Essas ações tendem mais ao afastamento do que a aproximação dos jovens aos textos literários.

Então quais seriam as estratégias para a aproximar jovens leitores dos textos literários? Como as TIC podem ser aliadas nesse processo? 


\section{Literatura e TIC}

Como forma de melhor situar o objeto de estudo, buscamos na literatura recente (últimos seis anos) algumas investigações que aproximam Literatura, enquanto disciplina, e utilização de recursos digitais. Recorremos a artigos revisados por pares e indexados à base de dados ERIC - Education Resources Information Center, uma vez que esses estudos oferecem grande fiabilidade. Como forma de melhor circunscrever os estudos de nosso interesse, optamos pela busca avançada, com a utilização da seguinte equação de pesquisa: (middle school OR elementary school) AND (computer mediated communication OR educational technology) AND (literature appreciation OR literacy education OR literature circles OR literature learning OR literature teaching).

Uma síntese das pesquisas relacionadas à nossa temática, com uma breve descrição, é apresentada no quadro abaixo:

Quadro 1 - Revisão de literatura

\begin{tabular}{|c|c|c|c|}
\hline $\begin{array}{c}\text { Título/autoria do } \\
\text { trabalho }\end{array}$ & Objetivos & Procedimentos & Resultados \\
\hline $\begin{array}{lr}\text { An } & \text { Action } \\
\text { Research Study } \\
\text { Involving } \\
\text { Motivating Middle } \\
\text { School Students } \\
\text { Learning through } \\
\text { Online Literature } \\
\text { Circles / Thomas } \\
\text { (2014) }\end{array}$ & $\begin{array}{lr}\text { Comparar } & \mathrm{a} \\
\text { motivação } & \text { de } \\
\text { alunos } & \text { que } \\
\text { participam de } & \text { círculos de } \\
\text { literatura on-line } \\
\text { com a motivação } \\
\text { daqueles que } \\
\text { participam } \\
\text { presencialmente } \\
\text { de círculos } \\
\text { literários } \\
\text { tradicionais }\end{array}$ & $\begin{array}{l}\text { Mediação docente, via Edmodo, entre } \\
\text { alunos de uma escola secundária e } \\
\text { textos literários por eles escolhidos a } \\
\text { partir de uma lista de livros. Na } \\
\text { plataforma, alunos assistiram a um } \\
\text { pequeno vídeo de apresentação das } \\
\text { obras como forma de incentivo à } \\
\text { leitura e discussão. Foi estabelecido } \\
\text { um cronograma de leitura para } \\
\text { indicação de quando e sobre que seção } \\
\text { do livro os alunos deveriam postar }\end{array}$ & $\begin{array}{l}\text { Os alunos que participaram dos } \\
\text { círculos de literatura on-line } \\
\text { estavam mais motivados em } \\
\text { comparação com os círculos } \\
\text { anteriores da literatura } \\
\text { presencial, entre outras razões, } \\
\text { porque o pensamento crítico foi } \\
\text { incentivado e apoiado por } \\
\text { colegas e professores. }\end{array}$ \\
\hline $\begin{array}{l}\text { How Does the Use } \\
\text { of Blogs Impact } \\
\text { Student } \\
\text { Motivation for } \\
\text { Literature } \\
\text { Discussions?/ } \\
\text { Panes (2014) }\end{array}$ & $\begin{array}{l}\text { Determinar o } \\
\text { impacto dos blogs } \\
\text { na motivação dos } \\
\text { alunos para } \\
\text { discutir literatura }\end{array}$ & $\begin{array}{l}23 \text { alunos de uma escola primária } \\
\text { foram divididos em } 3 \text { subgrupos para } \\
\text { leitura de obras literárias distintas de } \\
\text { uma mesma escritora. Todos } \\
\text { receberam instruções sobre elementos } \\
\text { de uma discussão literária. Nas } \\
\text { primeiras duas semanas todos } \\
\text { deveriam publicar no blog e fazer } \\
\text { discussões presenciais. Nas } 4 \text { semanas } \\
\text { seguintes poderiam escolher uma } \\
\text { dessas formas de interação. Além do } \\
\text { blog criado para a discussão sobre as } \\
\text { obras indicadas, havia outro em que os } \\
\text { alunos poderiam postar comentário } \\
\text { sobre leituras independentes. }\end{array}$ & $\begin{array}{l}\text { A discussão literária via blog } \\
\text { não necessariamente impactou } \\
\text { na motivação dos estudantes. } \\
\text { Suas escolhas foram } \\
\text { determinadas muito mais por } \\
\text { percepções e habilidades } \\
\text { individuais. A autora concluiu } \\
\text { que um método por si só não é } \\
\text { mais motivador que o outro e } \\
\text { que alguns alunos podem } \\
\text { prosperar no uso de TIC, } \\
\text { enquanto outros irão preferir } \\
\text { uma interação presencial. }\end{array}$ \\
\hline
\end{tabular}

Literature Circles 2.0: Updating a Classic Strategy for the 21st Century/ Herrera e Kidwell (2018)

V. $18 \mathrm{~N}^{\circ} 1$, julho, 2020

Propor uma nova visão sobre os círculos de literatura tradicional, que os autores chamam Literature Circles 2.0. Essa abordagem tem como fundamentos
Os autores fazem uma revisão de literatura que aponta as vantagens da utilização dos círculos de literatura como estratégia para engajar alunos para discussão de textos literários. Os estudantes são agrupados e assumem papéis específicos, como Diretor de discussão, Ilustrador, Pesquisador etc. Os pesquisadores reconhecem a eficácia dessa estratégia, mas destacam que muitos aspectos
Para acompanhamento da leitura a ser realizada pelos alunos, os pesquisadores sugerem que os professores elaborem questões que ajudem os alunos a se conectarem com a obra. Recomendam nessa etapa o uso das aplicações Edmodo ou o Google Classroom como ambiente; o Google Quizzes ou o Quizlet, para verificação da DOI: 


$\begin{array}{lll}\text { importância da } & \text { provavelmente parecerão obsoletos } & \text { contribuição de cada um no } \\ \text { tecnologia, } & \text { para os alunos de hoje e, por isso, grupo. Os autores apontam } \\ \text { multiculturalismo } & \text { propõem uma atualização dos papéis } & \text { ainda algumas tarefas a serem } \\ \text { e } & \text { assumidos pelos alunos e das } & \text { desenvolvidas pelos alunos nos } \\ \text { desenvolvimento } & \text { ferramentas que podem ser utilizadas. } & \text { papéis de gestor de projetos, } \\ \text { de habilidades do } & & \begin{array}{l}\text { designer gráfico, } \\ \text { Tweeter, Trend-Spotter etc. Na }\end{array} \\ \text { século XXI } & \text { execução das atividades, o } \\ & \text { Twitter, Blog e o Canva seriam } \\ & \text { alguns dos aplicativos } \\ \text { utilizados. }\end{array}$

Fonte: autores (2020)

As pesquisas apresentadas revelam o potencial das TIC para aprendizagem de literatura e, mais que isso, oferecem algumas pistas que devem ser observadas quando da propositura de projetos para tal finalidade. Se, por um lado, Thomas (2014) percebeu maior engajamento nas discussões on-line quando comparadas às presenciais, Panes (2014) percebeu que a utilização do blog não foi determinante para a motivação dos alunos e que muitos deles prosperavam mais por meio de uma interação presencial, o que nos leva a crer que as experiências de ensino e aprendizagem mediadas por um modelo híbrido podem ser mais vantajosas por estimularem as diversas formas de aprender.

A pesquisa de Herrera e Kidwell (2018) chama a atenção para a atualização de métodos que foram e, de certa forma, ainda são exitosos no presente, mas que precisam estar em consonância com as demandas da sociedade hodierna, especialmente no que tange à colaboração, ao uso de recursos digitais e ao reconhecimento de um mundo multicultural. Nessas investigações, assume importância o trabalho de planejamento e acompanhamento realizado pelos docentes, como a indicação de obras literárias, elaboração de questões norteadoras das discussões e das tarefas a serem executadas e seleção das aplicações. Essa mediação docente deve ser estimulada. Corroboramos a ideia de que a seleção de livros, a definição de objetivos de aprendizagem, bem como o levantamento de questões sobre uma obra literária não atrapalham a experiência estética dos alunos, ao contrário, potencializam-na e garantem a sistematização da aprendizagem, necessária no ambiente escolar.

A atitude responsiva/ativa diante do texto literário deve ser estimulada por meio de metodologias que, igualmente, desafiem os alunos a assumirem um papel ativo na aprendizagem. Nesse sentido, as chamadas metodologias ativas favorecem a criação de cenários nos quais "o aluno se torna protagonista e assume mais responsabilidade sobre seu processo de aprendizagem (e o professor se torna um guia ao lado)" (MATTAR, 2017, p.21). No caso do ensino de literatura, guiar significa mediar as leituras e propor atividades, em torno dos textos lidos, que possam dar notícia de uma interpretação individual, crítica e reflexiva, a ser compartilhada com o grupo. Nessa troca, a percepção individual é ampliada pelo olhar do outro (alunos e professor), criando-se, desse modo, uma comunidade de leitores. E esse processo pode, sem dúvida, ser enriquecido pelo uso das TIC, conforme proposta apresentada adiante.

\section{Metodologia}

A investigação tem caráter exploratório e descritivo, objetiva uma maior familiarização com um campo de estudo e, neste caso, uma prospecção tanto para a aplicação de uma estratégia de trabalho para a disciplina de Literatura na educação básica, quanto para a realização de novas investigações que almejem aplicar e avaliar os resultados do que aqui é proposto. Esse tipo de pesquisa visa ainda, segundo Gil (2008), a formulação de V. $18 \mathrm{~N}^{\circ} 1$, julho, 2020 RENOTE DOI: 
problemas mais específicos para estudos posteriores.

Após a definição das questões de investigação e tendo como norte o letramento literário proposto por Cosson (2019), traçamos o design de investigação:

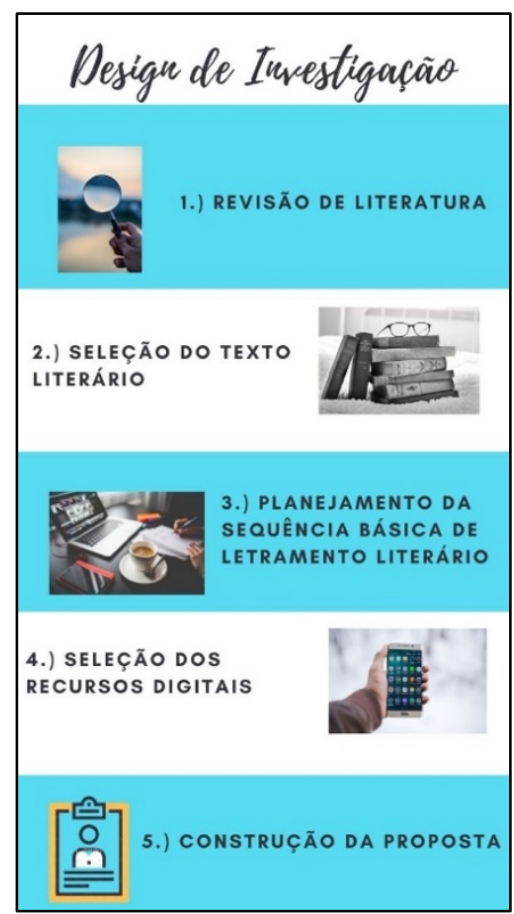

Figura 1 - Design de investigação

A revisão de literatura, além de permitir a identificação de contributos e lacunas de investigações já realizadas, permite, ainda, segundo Bento (2012), um ganho de perspectivas metodológicas. A partir da seleção, leitura e análise de alguns artigos científicos indexados pela base de dados ERIC, percebemos que, embora todas as investigações pudessem explorar o potencial que a aprendizagem móvel oferece, isso não foi feito. Ainda sobre as perspectivas metodológicas, uma pista interessante que verificamos é que houve planejamento e acompanhamento das atividades de leitura, incluindo a indicação de obras literárias, algo que consideramos salutar e que norteou o desenvolvimento desta proposta.

Sobre a seleção do texto literário, recorremos à análise feita por Moraes e Feitosa (2010) do conto "Um rastro do teu sangue na neve", de Gabriel García Márquez, como uma das fontes para a elaboração do roteiro de aprendizagem. Essas autoras, embora não trabalhem o aspecto pedagógico do conto ou proponham qualquer forma para sua abordagem em contexto escolar, apresentam uma interessante análise que suscita várias possibilidades para leitura e estudo desse texto. As perspectivas que orientam nossa proposta dizem respeito à experiência enquanto aprendizagem e a relação o que o indivíduo estabelece com o espaço/lugar. Não se trata aqui de tentar "moldar" a leitura de um texto literário, mas tão somente reconhecê-lo como, entre outros aspectos, uma forma de conhecimento de si e do outro e passível, especialmente em contexto escolar, de uma leitura mais sistemática. Esta, a partir da mediação docente, estimula a fruição estética, leitura reflexiva, interculturalidade, ampliação do olhar para o mundo e, consequentemente, formação de leitores críticos, mais "ricos".

Para o planejamento do roteiro de aprendizagem aqui apresentado, recorremos à sequência básica de letramento literário, proposta por Cosson (2019). A palavra letramento é uma tradução do inglês literacy para português do Brasil. Em Portugal, utiliza-se o termo literacia. Grosso modo, o letramento é um conjunto de práticas sociais V. $18 \mathrm{~N}^{\mathrm{o}} 1$, julho, 2020 RENOTE DOI: 
das quais os indivíduos participam efetivamente frente às demandas de seu tempo. Essas práticas são múltiplas e agregam diversificados signos e linguagens. Daí, falar-se em letramento, letramento científico, informacional, visual, político, digital etc. Vários pesquisadores já se debruçaram sobre o tema e seus desdobramentos (eg., SOARES, 2009; RAMOS; FARIA, 2012; RIBEIRO; COSCARELLI, 2017). O intuito aqui não é aprofundar essa discussão, mas apenas reconhecer a existência de múltiplos letramentos e situar especificamente aquele proposto por Cosson (2019), o letramento literário.

Observadas as etapas de uma sequência básica de letramento, buscamos na literatura e na Web sites e aplicativos que pudessem potencializar a motivação, introdução, leitura e interpretação de um texto literário. Foram utilizados ainda como critérios de seleção a gratuidade e disponibilidade para dispositivos móveis.

A viabilidade desta proposta depende, para além das questões pedagógicas, das condições de acesso de alunos e professores a dispositivos como computadores, smartphones, tablets etc. conectados à Internet, preferencialmente, tanto em ambiente escolar, quanto em ambiente doméstico. Depende ainda do domínio das ferramentas sugeridas, o que, certamente, demanda investimento de tempo dos sujeitos envolvidos.

Na seção seguinte apresentamos os resultados desta pesquisa.

\section{Rastros para a aprendizagem de literatura}

O texto selecionado, "Um rastro do teu sangue na neve", é de autoria do escritor colombiano Gabriel García Márquez, prêmio Nobel de Literatura e reconhecido em muitos países pela sua qualidade literária. O texto faz parte da obra intitulada Doze contos peregrinos. As histórias narram situações insólitas de personagens latino-americanos no continente europeu. Esse contexto pode eventualmente não estar próximo da realidade de jovens do ensino secundário de determinada escola, pode inclusive não fazer parte do universo que interessa a muitos deles. No entanto, a dimensão formativa da leitura responsabiliza educadores, conforme Gamboa (2016), por escolhas que libertem os alunos do confinamento de suas experiências. Nesse sentido a leitura literária é sempre um convite para ampliação do olhar e da experiência, para o exercício do (auto) conhecimento e deve ser encorajada e mediada em contexto escolar.

Uma possibilidade para essa mediação é o desenvolvimento de uma sequência básica de letramento literário, proposta por Cosson (2019) e constituída por quatro etapas: motivação, introdução, leitura e interpretação.

A motivação consiste em uma preparação para que o aluno "entre" no texto. As situações propostas pelo professor devem estabelecer laços com o texto que será lido e podem solicitar dos alunos uma resposta a uma questão ou posicionamento diante de um tema. A introdução apresenta informações panorâmicas sobre o autor e a obra. Cosson (2019) recomenda ainda a apresentação física do livro, momento em que o professor chama a atenção do aluno para a leitura da capa, orelha, contracapa e outros elementos paratextuais que podem fornecer "caminhos". Durante uma leitura inicial coletiva, hipóteses serão levantadas, que serão comprovadas, refutadas ou ampliadas após a leitura da obra.

A leitura literária mediada pela escola pressupõe um acompanhamento. Durante uma leitura mais longa, como um romance, por exemplo, o professor deve fazer intervalos e convidar os alunos a apresentar os resultados parciais dessa experiência. Um texto mais curto, como é o caso do conto, pode ser lido integralmente em sala de aula.

A interpretação divide-se em dois momentos: um interior e outro exterior. O primeiro é o encontro do leitor com a obra literária. Esse momento, embora seja "individual", não é impermeável a influências, uma vez que já fora afetado pelas etapas anteriores, bem como por sua própria história de vida de aluno-leitor e por seus conhecimentos prévios. Por isso 
a leitura é sempre um ato social.

O segundo momento da interpretação é, nas palavras de Cosson (2019, p. 65), "a concretização, a materialização da interpretação como ato de construção de sentido de uma determinada comunidade."

O quadro abaixo apresenta uma síntese dessas etapas, aplicadas ao conto em questão, com os recursos selecionados:

Quadro 2 - Etapas da proposta

\begin{tabular}{|c|c|c|c|}
\hline Etapas & Propósitos & Estratégias & Recursos/Linguagem \\
\hline Motivação & $\begin{array}{l}\text { Preparar o leitor para "entrar" no } \\
\text { texto }\end{array}$ & $\begin{array}{l}\text { Elaboração um } \\
\text { glossário visual da } \\
\text { palavra Peregrino }\end{array}$ & $\begin{array}{l}\text { Padlet, Smartphone, PicsArt e } \\
\text { Fotor, YouTube. }\end{array}$ \\
\hline Introdução & $\begin{array}{l}\text { Apresentar informações } \\
\text { panorâmicas sobre o livro de contos, } \\
\text { o conto selecionado e o autor; } \\
\text { Convidar os leitores para lerem o } \\
\text { texto }\end{array}$ & $\begin{array}{l}\text { Criação de uma } \\
\text { animação }\end{array}$ & Padlet, Powtoon e Wikipedia, \\
\hline Leitura & Ler individualmente e em grupo & $\begin{array}{l}\text { Disponibilização do } \\
\text { conto em um } \\
\text { Website e leitura } \\
\text { coletiva a partir de } \\
\text { um podcast }\end{array}$ & $\begin{array}{l}\text { Padlet, livro impresso, } \\
\text { Smartphone, } \\
\text { SoundCloud }\end{array}$ \\
\hline Interpretação & $\begin{array}{l}\text { Registrar e compartilhar a leitura } \\
\text { com outros leitores; }\end{array}$ & $\begin{array}{l}\text { Fórum de discussão; } \\
\text { Painel literário }\end{array}$ & $\begin{array}{l}\text { Padlet, Smartphone, YouTube, } \\
\text { Audio Library, Filmora Go }\end{array}$ \\
\hline
\end{tabular}

Fonte: autores (2020)

A ferramenta Padlet é um mural virtual no qual, além da gratuidade, a facilidade para armazenar, produzir e compartilhar conteúdo multimodal são atrativos. Pode funcionar como um ambiente virtual de aprendizagem e tem o trabalho colaborativo e a interação, por meio de comentários e reações, grandes atrativos para o processo de ensino e aprendizagem. A ferramenta fornece, segundo Fuchs (2014), um espaço não-ameaçador para a curadoria do trabalho colaborativo em sala de aula. No desenvolvimento deste trabalho, a ferramenta foi utilizada em todas as etapas e agrupa os hiperlinks com as instruções dadas e os aplicativos sugeridos. A tela inicial é ilustrada na figura abaixo:

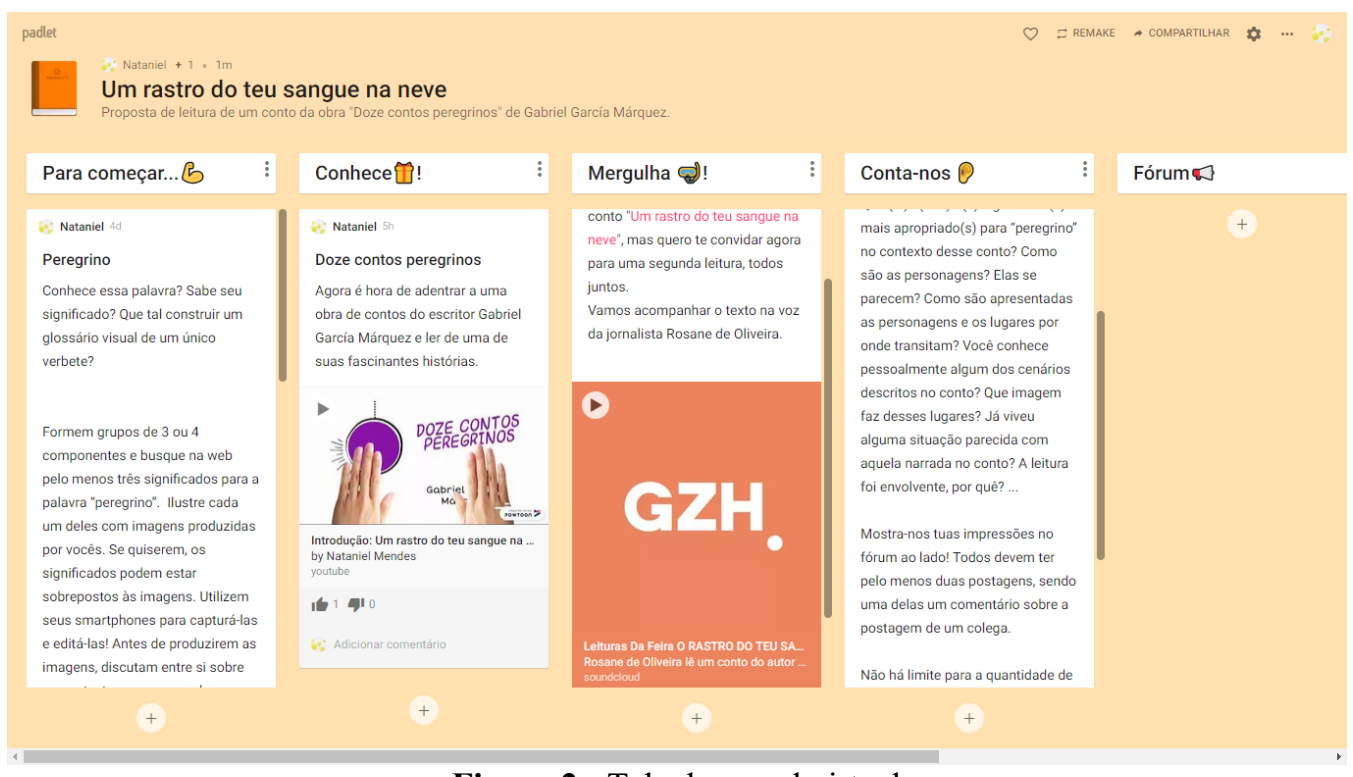

Figura 2 - Tela do mural virtual 
O mural está disponível para consulta no endereço https://cutt.ly/ZpH4nSY.

As etapas aqui descritas seguem uma progressão que vai desde à preparação para a leitura ao aprofundamento e partilha das interpretações. Visam, por meio da mediação docente, orientar a reflexão sobre a leitura literária, a partir de questões sobre a experiência enquanto aprendizagem, a relação o que o indivíduo estabelece com o espaço/lugar e outras que possam emergir durante a leitura. Essas questões fornecem algum caminho para que o aluno reflita sobre o texto lido e, ao mesmo tempo, consiga construir suas próprias questões que, ao serem socializadas, serão alvo de comentários e novas questões, o que no nosso entender enriquece a experiência literária.

Para a etapa de motivação, recorremos à elaboração de um glossário visual. Os alunos deveriam consultar dicionários e produzir com seus smartphones 3 imagens associadas a três significados do vocábulo peregrino. Já na primeira etapa dessa proposta os alunos são convidados/desafiados a pesquisar na Web, fotografar com seus smartphones e produzir conteúdo que tem a criação de imagens no seu cerne. A imagem dentro do processo pedagógico, quando utilizada convenientemente, segundo Lencastre e Chaves (2003), possibilita uma melhor compreensão e facilita a aquisição de conhecimentos.

Neste caso, acreditamos que a descoberta de significados de um vocábulo e sua associação a uma imagem original, além de possibilitar a compreensão e ampliação desses significados, estimula uma postura ativa do educando e apresenta uma das tantas possíveis portas de entrada para o texto literário que será lido.

Nesse sentido, a convergência entre uma metodologia ativa e tecnologias em educação tende, conforme Mattar (2017), a ser um diferencial que leva alunos a refletirem sobre suas práticas e a abandonarem a posição de recipientes passivos.

Nesse processo, o smartphone é um parceiro de alunos e professores. $\mathrm{O}$ uso no processo pedagógico de dispositivos móveis, conectados ou não à Internet, agrega, a partir de um planejamento bem delineado, experiências de aprendizagem significativas. Claro que esses dispositivos quando conectados à Internet oferecem maiores possibilidades.

Para o desenvolvimento desta proposta, o smartphone pode ser utilizado em todas as etapas do processo, percorrendo atividades como: acesso ao mural virtual, captura, edição de imagens, execução e compartilhamento das tarefas, interação com outros leitores etc. Os smartphones, bem como as demais tecnologias móveis, "têm o potencial de apoiar actividades de aprendizagem individual e colaborativa e os processos de criação de conhecimento de forma eficaz." (Moura, 2010, p. 488). A mesma autora adverte que as estratégias de aprendizagem e a criação coletiva de conhecimento que as tecnologias móveis medeiam são mais importantes do que as ferramentas em si.

Corroboramos essas ideias, apresentando os recursos selecionados após a elaboração das estratégias e busca na Web e na literatura acadêmica por aplicativos que pudessem potencializar a aprendizagem em cada etapa. Compreendemos que as TIC, especialmente a Web, são mais que um recurso, mas uma linguagem cada vez mais comum no cotidiano de boa parte da população do planeta e que tem os jovens como principais usuários.

$\mathrm{Na}$ etapa de introdução, recorremos ao Powtoon, que "é uma ferramenta que permite cativar o público uma vez que, normalmente, gera entusiasmo, capta a atenção e disponibiliza ao utilizador um conjunto de recursos que permitem animar o vídeo" (Cruz 2015 , p. 248). Cativar e entusiasmar a jovem audiência para a leitura de uma obra literária é o que se espera que seja feito, enquanto etapa incipiente, nas aulas literatura.

$\mathrm{Na}$ etapa de leitura, os alunos, se tiverem acesso, podem ler o livro impresso. A ascensão de recursos digitais e disponibilidade de informações na tela de smartphones e computadores não suplantou a tecnologia impressa. Santaella (2003) afirma que uma nova formação comunicativa não asfixia as anteriores, mas causa-lhes reajustamentos e refuncionalizações. A dicotomia entre impresso e digital não parece salutar. O melhor é 
aproveitar o que cada suporte, com suas linguagens, pode oferecer e operar para a construção de conhecimentos.

Além do livro impresso, há no mural links para acesso ao texto e a um podcast com a leitura do conto na íntegra, que pode ser realizada coletivamente em sala de aula.

Para a etapa de interpretação, recomendamos um fórum de discussão dentro do próprio mural com questões levantadas pelo professor e pelos alunos, além da elaboração de painel literário a ser compartilhado no YouTube. Audio Library e Filmora Go são alguns dos aplicativos recomendados.

É nessa etapa do letramento literário que consideramos que as TIC podem dar maior contributo. A partilha da interpretação em uma comunidade de leitores amplia os significados construídos, a priori, individualmente e faz com que esses alunos-leitores tomem consciência de que são parte de uma coletividade em que a troca, a colaboração e o diálogo são elementos que a fortalecem e legitimam essa comunidade.

\section{Considerações finais}

A criação de designs para experiências desta natureza demanda algum tempo e aprendizagem do professor, especialmente nas primeiras tentativas. Em contrapartida, esse tempo investido pode ser rentabilizado para outras experiências, algo que consideramos muito vantajoso. Soma-se a isso o entusiasmo que se espera que seja gerado no aluno-leitor para começar a se envolver nas tramas de um texto literário.

As TIC, especialmente as móveis, por seu caráter ubíquo, podem favorecer o encontro dos alunos com textos, mediar experiências de leitura, partilha de interpretações e formação de comunidades de leitores. Cabe aos professores-pesquisadores a busca por estratégias que aproveitem o seu potencial para aprendizagens significativas. Essa busca, conforme demonstrado neste trabalho, tem sempre como pressuposto fundamental o planejamento. Somente assim professores poderão tirar partido do que as TIC podem contribuir para o letramento literário dos jovens, bem como para a educação de modo geral.

A pesquisa tem como limite o fato de ainda não ter sido aplicada em um contexto real de aprendizagem. Por outro lado, fornece possibilidades para outros pesquisadores que queiram investigar sobre sequência expandida, avaliação, motivação para leitura de novos textos, estilos de aprendizagem, metodologias ativas, imagem e educação, dentre outros temas que o trabalho suscita.

\section{Referências}

BENTO, António. Como fazer uma revisão da literatura: Considerações teóricas e práticas. Revista JA (Associação Académica da Universidade da Madeira), v. 7, n. 65, p. 42-44, 2012.

CEREJA, W. R. Uma proposta dialógica de ensino de literatura no ensino médio. Tese (Doutorado em Linguística aplicada e Estudos da linguagem) - Centro de Ciências Humanas, Letras e Artes-São Paulo: Pontífica Universidade Católica de São Paulo (PUC/SP), 2004.

CHIAPPINI, Ligia. Leitura e construção do real: o lugar da poesia e da ficção. São Paulo: Cortez, 2002.

COSSON, R. Letramento literário: teoria e prática. São Paulo: Contexto, 2019. 
CRUZ, Sónia. Powtoon: apresentações criativas. In: CARVALHO, Ana Amélia Amorim (Org). Apps para dispositivos móveis: manual para professores, formadores e bibliotecários, 2015.p. 247-257

FUCHS, Beth. The writing is on the wall: using Padlet for whole-class engagement. LOEX Quarterly, v. 40, n. 4, p. 7, 2014.

GAMBOA, Maria José. À procura do leitor literário: textos e contextos de leitura. Exedra: Revista Científica, n. 2, p. 170-183, 2016.

GIL, Antonio Carlos. Métodos e técnicas de pesquisa social. 6. ed. Editora Atlas SA, 2008.

HERRERA, Luis Javier Pentón; KIDWELL, Tabitha. Literature Circles 2.0: Updating a Classic Strategy for the 21st Century. Multicultural Education, v. 25, n. 2, p. 17-21, 2018.

LENCASTRE, J. A.; CHAVES, J. H. Ensinar pela imagem. Revista GalegoPortuguesa de Psicoloxía e Educación, n.08, v.10, p. 2100-2105, 2003.

LUCAS, M.; MOREIRA, A. DigComp 2.1: Quadro Europeu de Competência Digital para Cidadãos: com oito níveis de proficiência e exemplos de uso. Aveiro: UA, 2017.

MATTAR, João. Metodologias ativas: para uma educação presencial, blended e a distância. São Paulo: Artesanato Educacional, 2017.

MORAES, Cláudia Letícia Gonçalves; FEITOSA, Márcia Manir Miguel. O rastro do teu sangue na neve: o processo de percepção de si pela experiência. Cadernos de Pesquisa, v. 17, n. 2, 2010.

MOURA, Adelina Maria Carreiro. Apropriação do telemóvel como ferramenta de mediação em mobile learning: estudos de caso em contexto educativo. Tese (Doutoramento em Ciências da Educação, Área de Conhecimento em Tecnologia Educativa). Universidade do Minho, 2010

PANE, Pamela et al. How does the use of blogs impact student motivation for literature discussions. Journal of Inquiry and Action in Education, v. 5, n. 3, p. 5, 2014.

RAMOS, Altina; FARIA, Paulo. Literacia digital e literacia informacional: breve análise dos conceitos a partir de uma revisão sistemática de literatura. Revista Linhas, v. 13, n. 2, p. 29-50, 2012.

RIBEIRO, Ana Elisa; COSCARELLI, Carla Viana. Letramento digital: aspectos sociais e possibilidades pedagógicas. Autêntica, 2017.

SANTAELLA, Lúcia. Da cultura das mídias à cibercultura: o advento do póshumano. Revista Famecos, v. 10, n. 22, p. 23-32, 2003.

SOARES, Magda. Letramento-um tema em três gêneros. Autêntica, 2009.

FALTER THOMAS, Angela. An action research study involving motivating middle school students'learning through online literature circles. Journal of Ethnographic \& Qualitative Research, v. 9, n. 1, 2014.

TODOROV, Tzvetan. Literatura em perigo. Trad. Caio Meira. Rio de Janeiro: DIFEL, 2014. 